\title{
Síndrome de Mounier Kuhn
}

\author{
Mounier-Kuhn syndrome
}

Geovanny Hernández, Franco Ruales, Leslie Vargas, FaIVER RamíREZ • BOgOtÁ, D.C.
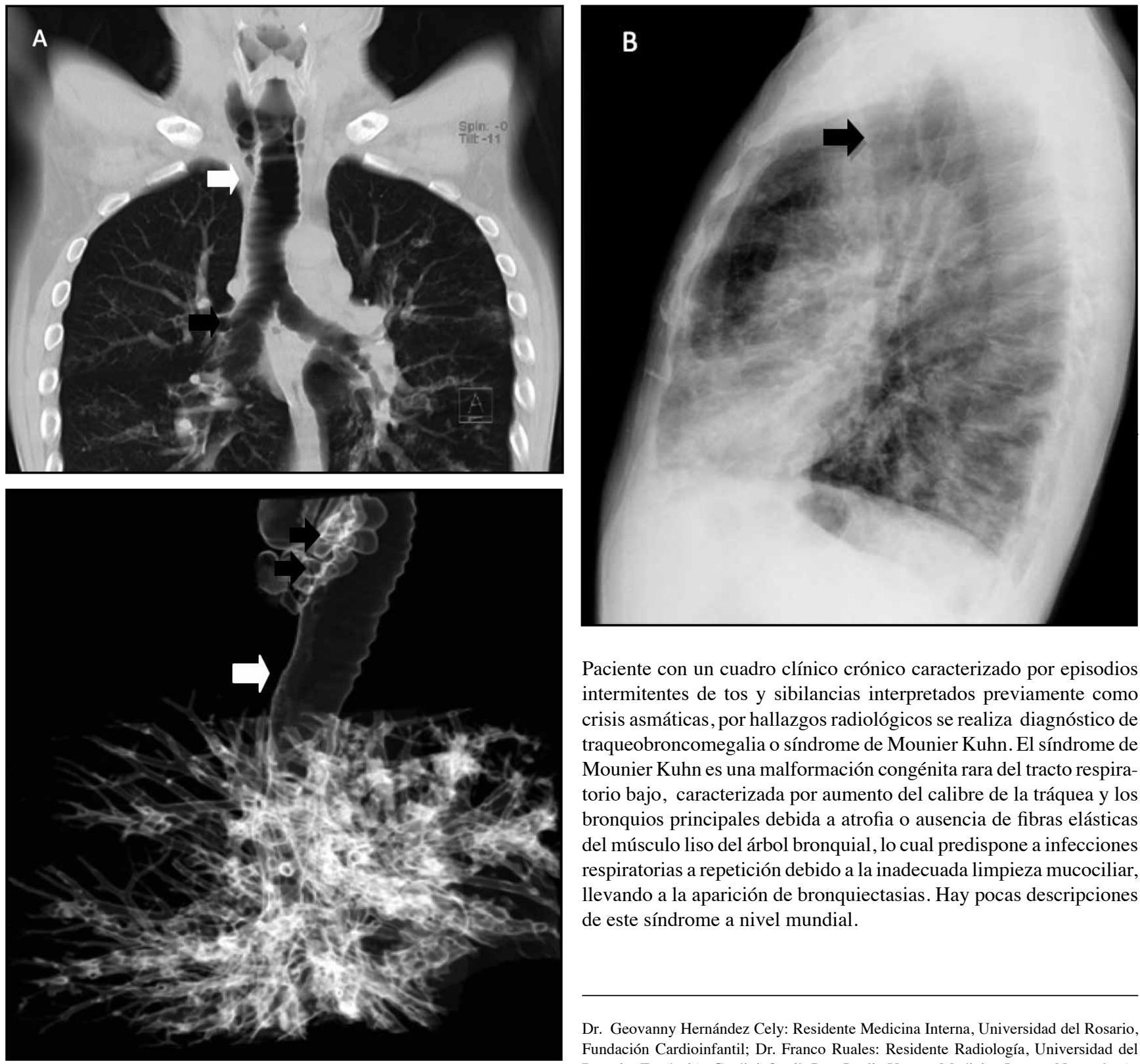

Paciente con un cuadro clínico crónico caracterizado por episodios intermitentes de tos y sibilancias interpretados previamente como crisis asmáticas, por hallazgos radiológicos se realiza diagnóstico de traqueobroncomegalia o síndrome de Mounier Kuhn. El síndrome de Mounier Kuhn es una malformación congénita rara del tracto respiratorio bajo, caracterizada por aumento del calibre de la tráquea y los bronquios principales debida a atrofia o ausencia de fibras elásticas del músculo liso del árbol bronquial, lo cual predispone a infecciones respiratorias a repetición debido a la inadecuada limpieza mucociliar, llevando a la aparición de bronquiectasias. Hay pocas descripciones de este síndrome a nivel mundial.

Dr. Geovanny Hernández Cely: Residente Medicina Interna, Universidad del Rosario, Fundación Cardioinfantil; Dr. Franco Ruales: Residente Radiología, Universidad del Rosario, Fundación Cardioinfantil; Dra. Leslie Vargas: Medicina Interna-Neumología, Fundación Neumológica Colombiana; Dr. Faiver Ramírez Bríñez: Medicina Interna, Fundación Cardioinfantil. Bogotá, D.C.

Correspondencia: Dr Geovanny Hernández Cely, Calle 163 A N 13B-60, Fundación Cardioinfantil, Servicio de Medicina Interna. Telefono: 6672727 Ext 4500. Bogotá, D.C. E-mail: geova_h@yahoo.com

Recibido: 17/II/2011 Aceptado: 21/II/2011 